\title{
DEFINING THE DYNAMICS
}

Deborah Middleton

This chapter further expands upon the analysis of the dynamics contained in 'At Play in the Cosmos' (2001) and 'Secular Sacredness' (2008), drawing on my further practical experiences, conversations, and interviews with Núñez and Guardia over the last decade. I attempt here to bridge the gap between Part One and 'At Play in the Cosmos', by offering some further insight into the genesis of the dynamics; I also publish here, for the first time, a full list of the dynamics, and both summarise and extend what has gone before in terms of delineating their defining features.

Although the term 'dynamic' barely appears in Part One of this book, in the chapter on Anthropocosmic Theatre, Núñez introduced some of the principles underlying the dynamics - the anthropocosmic frame, the notion of sensitisation exercises, and key tools of the Taller such as vibration and contemplative running (or 'trotting'). Part One also includes accounts of theatrical events which carry names later used to designate specific dynamics; for example, Tonatiuh and Huracán are described as 'schemes of participatory theatre' (p. 114 above), Tloque Nahuaque is mentioned in passing as a 'work' (p. 108 above), and Citlalmina is described as a 'tool for (mental) training', and as the basis for a participatory theatre production in 1989 (p. 137 above). Within the descriptions of Tonatiuh, Huracán and Citlalmina as participatory productions, it is possible to discern the core structures that represent the dynamics of those names: Tonatiuh (pp. 116 - 120 above) seems to have consisted largely of the series of actions which I described in 'At Play in the Cosmos' (pp. 164 - 169 above); Huracán is described as involving a number of devices and experiences which were unique to the theatre event, but the core Huracan dynamic - which consists of a sequence of alternating cycles of contemplative running and the construction of a complex rhythmic pattern of three moving, concentric circles - is described as forming one part of the experience (pp. 126 - 129 above). 
Similarly, the theatrical event, Citlalmina, included 'a circuit' of the dynamic of that name within a broader aesthetic experience (p. 138 above).

From the earliest explorations, Núñez and his collaborators were, in fact, developing sequences of psychophysical actions which could be embedded within participatory theatre events, or shared in workshop settings (indeed, prior to the adoption of the word 'dynamic', the practices were simply referred to as workshop sessions (Middleton, 2018, $n p$ ).

According to Núñez, 'Every dynamic was born from the contact with a sacred tradition; [from the] techniques of ecstasy that Eliade talks about' (Middleton, 2018, np). The earliest researches within performative spiritual traditions to have influenced the dynamics include Núñez's exploration of Gurdjieff's work, and Guardia's practice within the Sufi tradition, as well as their collective exploration of conchero (shell) dancing. Guardia told me, 'The dynamics began to appear through contact with the concheros, whirling dervishes, howling dervishes...' (Middleton, 2018, $n p$ ). From these initial sources, they derived 'breathing exercises, singing, praying, whirling exercises' (Guardia in Middleton, 2018, $n p$ ).

Between 1978 and 1981, both Núñez and Guardia worked with Grotowski ${ }^{35}$ on experiences which would richly feed and support the development of the dynamics. In Theatre of Sources, Núñez developed the contemplative run, which would become a dominant technique in the Taller's toolbox. Guardia worked on 'The Movements' ${ }^{36}$ - 'a flowing sequence of yoga asanas, performed slowly, with open visual awareness in a multi-directional pattern' (Middleton \& Núñez, 2018: 226). This sequence provided the Taller with 'a kind of anthology of asana-like postures, or psychophysical "gestures" (Middleton \& Núñez 2018: 229) for further exploration, and with a model for a form of meditation-in-movement through energetic positions that

35 In 1978, on Tree of People in Poland; in 1979, in the Mexican sierra; in 1980 - 1981, on Theatre of Sources in Poland; in 1985, at Iztaccíhuatl, Mexico. (See pp. 72 - 87 above)

36 The relationship between 'The Movements' and its later development as 'The Motions' in described in Middleton and Núñez, 2018. 
could act as a kind of 'key' to deeper dimensions of experience (Middleton \& Núñez 2018: 228).

In 1984, the first dynamic - Tonatiuh - was created. Described above (pp. 164 -169), Tonatiub synthesised these various early influences in a sequential meditation-in-movement form that included contemplative running from the phase with Grotowski, whirling derived from the Sufi training, and a closing sequence from the conchero tradition. As I explored in 'Secular Sacredness' (and as was Grotowski's model in Theatre of Sources), the practices that were derived from spiritual traditions were approached as pancultural, psychophysical techniques. The essence of the action was rigorously maintained, and practices were brought alongside each other (never mixed) in a containing structure.

The term 'dynamic' was introduced in the late 1990s to distinguish between a participatory sequence designed for a specific purpose within the aesthetics of a production, and such a sequence refined, set, and repeatable as a free-standing structure. Just as the key tools of the Taller - contemplative running, slow walking, (and various directional and other versions of these two), the use of closed eyes, conchero rhythmic stepping patterns, the Sufi whirling, vocal vibration - are the building blocks for dynamics, so too the dynamics themselves can be combined with other devices and performance materials to provide the participatory heart of the productions.

By 1997, Núñez had developed eighteen distinct dynamics (personal correspondence dated October 1997), each of which created a different energetic experience and embodied meditation for its participants. By 2001, when 'At Play in the Cosmos' was first published, twenty-one dynamics (p.157 above) were being practised in the thrice-weekly morning sessions, and also shared by Núñez in his workshops in Europe, Mexico, and Central and South America. Impressive as that total might be, it does not tell the whole story.

In 2016, speaking in Huddersfield, Núñez gave the total number of dynamics as 24 (p. 311 below) and in March 2018, I noticed that his working notebook contained a list of 28 . When asked, however, he continues to 
specify that there are 21 dynamics! In fact, the corpus of dynamics is in a continual process of refinement. Whilst Citlalmina, arguably the cornerstone of the Taller, is practised every Wednesday morning without fail, on the other mornings, Núñez cycles through the various dynamics; working with different emphases in different periods, exploring and refining existing sequences, and sometimes building new ones. He describes this as a 'chaotic', rather than a systematic process (Middleton, 2018, n.p.), and no doubt it is guided to some degree by the demands of the productions he is working on at any given time, by the sources he is currently studying, or by the needs of the particular individuals attending the Taller sessions at a given moment.

To be included in the official list, a dynamic must satisfy certain conditions: it will have been fully developed and refined, will have been given a specific name, and will be active in the Taller's current repertoire. For various reasons, a dynamic which might once have served an important function in the evolution of Núñez's practice may be set aside for a time. One example of this is the dynamic, Tensegrity, which was personally transmitted to Núñez and a small group of other Mexicans ${ }^{37}$ by its originator, Carlos Castaneda, in Mexico City in 1986. When Núñez presented workshops at the Centre for Performance Research symposium, 'Performance, Ritual and Shamanism' in Cardiff in 1993, Tensegrity was included, but by 1997, preferring to distance himself from commercial developments by Castaneda and his followers, Tensegrity had been withdrawn. ${ }^{38}$ In the past few years, however, Núñez has re-explored what he sees as the core of the exercise, sequencing it with the Taller's sensitization tools, and creating a new version of the dynamic, now called Nahui Ollin (Nahui - Four, Ollin - Movement in Nahuatl).

37 The group included Ana Luisa Solís and Helena Guardia, Núñez's long-term collaborators; Marco Antonio Karam, founder and director of Casa Tíbet in Mexico City, and Jacobo Grinberg, a Mexican scientist and writer whose disappearance in 1994 is the subject of ungoing speculation.

38 Personal correspondence from Núñez to Middleton, dated October 1997, lists 18 dynamics, with Tensegrity crossed out. 
At the time of going to press, there are 22 dynamics on Núñez's official list. Since he expresses a preference for the 'auspiciousness' of the number 21 (Middleton, 2018, n.d.), the following, currently definitive list of the dynamics follows the example of the Tarot Major Arcana with numbering beginning at ' 0 '.

\section{The Dynamics}

\begin{tabular}{|l|l|}
\hline 0. Citlalmina & 11. Huracán \\
\hline 1. Tonatiuh & 12. Kikiriki \\
\hline 2. Queztalcoatl & 13. Moyocoyatzin 1 \\
\hline 3. Cadoceo & 14. Moyocoyatzin 2 \\
\hline 4. Nahual & 15. Mictlantecutli \\
\hline 5. Nanahuatzin & 16. In Ixtli In Yolot \\
\hline 6. Olmeca I & 17. Tezcatl \\
\hline 7. Tezcatlipoca & 18. Monotza \\
\hline 8. Ixpapalotl & 19. Tloque Nahuaque \\
\hline 9 Teozintle & 20. Xochipilli \\
\hline 10. In Teotl & 21. Nahui Ollin \\
\hline
\end{tabular}

\section{Defining the Dynamics}

In 'At Play in the Cosmos,' the dynamics are described as: 'structured sequences of psychophysical actions' (p. 184); with an inner and outer score (p. 189); involving a pre-Hispanic mythological image; and combining the tools of the Taller in various ways (p. 189). The key features are identified as 'continuous movement, continuous mental focus..., changing rhythms, and alternation between tension and relaxation' (p. 193).

In this short section, I would like to go further in exploring the defining features of the dynamics, by discussing three aspects which Núñez identified as crucial in an interview in 2018. These are: the inner score of foundational attitudes and inquiries; the pre-Hispanic names/images; and what Núñez describes as 'the raising and focusing of physical and mental energies' (Middleton, 2018, n.d.). References to all three of these aspects can be 
found throughout this book; my intention here is to bring together some focused discussion with brief descriptions of some of the dynamics, by way of illustration.

\section{Inner Foundations}

The particular steps, sequences, repetitions and rhythms of a given dynamic emerge through assiduous practical research and are carefully refined; nevertheless, as psychophysical technologies their efficacy cannot be reduced to physical protocols. The inner score is essential to the dynamic. How a dynamic is carried out is, for Núñez, more important than its physical dimensions. In guiding a practice, Núñez rarely gives detailed instruction on the physical actions, but continually coaches the participant with regard to the sustained mental and attitudinal activity that constitutes their inner work. Typically, there are repeated prompts regarding, for example, 'mindfulness', the raising of energy, and the sustaining of the 'will to work': Pay attention! Don't automaticise your work! Here and Now! This is Working Time! Free [mental] association is not allowed! This constitutes a continual call to mindfulness, the practice of which has formed a key part of Núñez's work from the earliest beginnings.

Each of the dynamics contains a core of personal challenge structured around three incremental stages of inner inquiry, (some dynamics emphasise one stage over the others in their overall function). These are:

- Know Yourself

- Control Yourself

- Project Yourself - 'I can because I think I can'.

In 'Mandala', Núñez attributes these directives to the three-part structure of both the Eleusinian rites and the ancient Mexican rites of the cult of Tlaloc (p. 298 below). They form the basis for an inner score - a contemplative inquiry which is carried in the embodied actions of the dynamic, and which asks the actor to make an honest encounter with herself. The fundamental task of the actor in training begins, for Núnez, by looking within. 


\section{Know Yourself}

'Know Yourself' is the first - the foundational - directive for the participant, but it could also be seen to be the over-riding inquiry to which the dynamics cycle back time and again. At the most basic level, the participant is asked to bring their attention to bear on their present moment experience, and to discover what they can of their own tendencies and distractions - what Núñez often calls 'distorted perceptions' and 'ego games'. This is not to suggest a process of self-analysis, but rather a close observation of oneself in action. In this way, the inner structure of the dynamics functions as a form of meditation. ${ }^{39}$

In his book, Rhythm in Acting and Performance, Eilon Morris describes his first encounter with the dynamics in 2004, and the way in which they acted upon his self-knowledge.

The work confronted many of my understandings of performance and acting, as well as the philosophical and spiritual ideas I had regarding how I related to the world and to myself within it. We were repeatedly asked to let go of preconceptions and expectations, to break out of our automatic patterns of behaviour and to surrender control while also attempting to master our physical and mental behaviours. While, at the time, I struggled to grasp many of these propositions intellectually, my practical encounters - the ways in which I was directed to perceive and engage with myself and my environment - had a profound impact on my embodied understanding of myself as a performer and a person (Morris, 2017: pp. 167-168).

The embodied nature of the self-encounter offered by the dynamics is crucial to an understanding of how they function; the self-knowledge that can be arrived at is an embodied knowledge, and thus represents a transformation

39 For an analysis of Núñez's practice in relation to Vajrayana Buddhist practice, see Middleton, D. \& Plá, D. (2018) 'Adapting the Dharma: Buddhism and Contemporary Theatre Training', Journal of Global Buddhism Vol. 19, 2018, pp. 113 - 125. 
of the individual's experiential bodymind. This sense that the dynamics represent an arena for personal transformation was reflected in the title of a workshop Núñez taught in Huddersfield in 1996 - 'Theatre as a Personal Rite'; the concept is discussed in 'High Risk Theatre' below (pp. 267 - 287). It is also evident in some of the snapshot accounts included here, such as acting teacher Edward McGurn's description of finding a source of personal healing in a residential workshop with Núñez in 2015.

\section{Control Yourself}

'Control Yourself' points to the challenge to sustain self-discipline and willpower. The dynamics, which each last approximately one hour, are often physically strenuous and require continual mental focus. The effort to avoid distractions and tiredness, and to go beyond one's first threshold of perceived limitations is implied in 'Control Yourself'.

The dynamic Moyocoyatzin 1: The One Who Constructs Himself gives a very clear example of the challenge to control oneself. The central action of the dynamic revolves around holding ones arms in the air for a long time. For most people (especially those carrying a lot of shoulder tension), the muscles quickly tire and begin to ache. This is, however, an example of what Núñez calls 'good pain' - not a sign that one is injuring oneself, but, rather, an intense somatic sensation which offers the invitation to engage ones determination and the power of mental focus (See pp. 274 - 276 for Núñez's discussion of good pain). In many of the dynamics, we come face to face with our own strength - or weakness - in relation to determination and self-control.

Control, though, should not be misunderstood as 'controlling'; indeed, Morris above refers to 'surrendering control'. It is not by egoic force, but rather by an internal process of renegotiating one's usual behavioural patterns, that the dynamics offer up their effects on the bodymind.

Through mindful observation of the self in action in the dynamics, the participant encounters the possibility that they might 'control' - that is, resist and even dismantle - those habitual impulses and self-limiting beliefs that 
do not serve them. What those impulses and beliefs are becomes abundantly clear through the immediate feedback provided by one's own mind and body on a moment-by-moment basis in the crucible-like container of the dynamic.

\section{Project Yourself or I Can, Because I Believe I Can}

Thirdly, and having taken these steps, the actor can present herself, and can project her presence and her energy in relationship with others, including an audience, and in performative ways. 'Project Yourself' includes the idea of creating so strong a mental intention that others (audiences, for example) can be moved by it. This is embodied in the dynamic, Tezcatlipoca.

Tezcatlipoca - the Smoking Mirror - (evoking an image of the shadow side), takes the form of a small, personal ritual of forgiveness (a version of the central mechanism of this dynamic was used in Cura de espantos - see pp. 173 - 177. Participants are given the task of forgiving each other through a symbolic action of removing sorrow and regret from their partner's heart, and metaphorically burning it. Núñez urges the participant to believe in the symbolic fiction; if we believe it, he tells us, then the ritual is effective - I can, because I think I can. This is the sense in which the actor 'projects' herself entering so fully into the 'as if' of her creative illusions that she makes them believable, and makes their effects tangible for herself and for others.

In fact, for Núñez, the notion of I can because I think I can is, at one and the same time, the Stanislavskian 'as if' and the technique 'used in rituals as vehicles to arouse another reality' (p. 54 above). Aligning Stanislavski with ritual devices, and understanding the power of meditative focus, Núñez takes very seriously the transformative potentials of the actor's art. To achieve this level of focused attention and inner commitment, however, it is necessary for the actor first to have worked through the levels of Know Yourself and Control Yourself.

The process of inwardly crossing the three thresholds of Know Yourself, Control Yourself, and Project Yourself constitutes the inner score of the dynamic, and is supported by cultivation of the foundational attitudes of mindfulness and focused intention. These foundations are themselves 
supported through an additional layer of imaginative engagement - typically in an image derived from pre-Hispanic mythology.

\section{Pre-Hispanic Names}

Almost all of the dynamics have a name drawn from pre-Hispanic mythology, ${ }^{40}$ in which is embedded a particular story or principle. Locating the work in pre-Hispanic Mexican culture is central to Núñez's project; from the very beginning, his research sought to redress the imbalance of the European influence on theatre in contemporary Mexico. Beyond this, the pre-Hispanic names key into the poetic and mythic philosophy and cosmology that provide the foundation from which the practices arise. This creates, for participants, a very particular kind of container for the psychophysical experiences that the work offers; whilst usually only lightly, and often playfully, evoked, the mythic figures and symbols create an invitation to participants to shift into an extra-daily engagement. In keeping with the language of the secular spiritual warrior which he also employs (pp. 277 - 278 below), the mythological dimension provides a strong impetus to, and support for, the will-power and serious play required to meet the challenge of the dynamics.

In his workshops and training residencies, Núñez generally introduces the dynamics without lengthy discussion or instruction. Sometimes the name alone is evocative: Ixpapalotl is the Solar Butterfly, and thus the 'flying' action that each participant is facilitated to explore in the course of the dynamic is imbued with the qualities of the lightness of a butterfly in sunshine.

Sometimes the dynamic has a particular story attached to it, and in sharing the story informally before the dynamic begins, Núñez also gently prompts the participant's imagination, and sets the metaphysical dimension for the experience. Kikiriki, for example, which is named after the Mexican onomatopoeic word for the cry of the rooster, is prefaced by a story about a conversation with a shaman in the Sierra: 'What is this life all about?' Nicolás

40 The current exceptions are 'Kikiriki', which is an onamatopeic word used in Spanish, and 'Cadoceo' (caduceus), for which Núñez expects a pre-Hispanic name to emerge in the future. 
asked the shaman, 'What is the meaning?' In that moment, a rooster crowed, as if in response. 'That', said the shaman, 'is the meaning'.

'The rooster knows what his role is', Nicolás tells us. 'He does his job and helps the flow of the Universe. We no longer know what our own Kikiriki is; we have to find it' (Middleton, 2016). The subtitle of Kikiriki is 'Find Your Life's Action'.

When Núñez tells this story in workshops, it is intended to cue participants to understand that the form of the dynamic is there to give them an opportunity to better know themselves through the revealing experience of working alone, in the context of others. The central action of the dynamic consists of moving, with eyes closed, in close proximity to the other workshop participants. Each person must find their own form of movement whilst having to negotiate around the other moving bodies nearby. The presence of others in this dynamic might be experienced as a hindrance, or as a helpful catalyst, or even as a support. (The interpersonal dimension is particularly heightened in Kikiriki, but the group is an important context throughout all of the dynamics).

The dynamic embodies, in a simple task, the necessity to find and sustain one's own authentic impulse whilst also adapting to an inter-personal context. Prefaced by the story, participants are unlikely to treat the dynamic merely as an improvisational exercise; the story seeds the invitation to reflect on one's experience allegorically; to treat the dynamic as a form of contemplation in movement.

Another example of a dynamic that is enhanced by its association with a story is Nanahuatzin, named after a character from Aztec mythology who volunteers to be the one to 'jump into the fire' and become the sun. When stronger, younger, seemingly more heroic warriors refuse the challenge, it is Nanahuatzin, a weak, old man, who reveals the inner strength and courage needed to make the sacrifice that will ensure the rising of the new sun (Nanahuatzin becomes the sun for our current epoch). Such stories provide an inner support to the participant in the challenge to 'make one's fight', as 
Núñez repeatedly describes the inner work. (In the snapshots that follow, Tray Wilson and Karoliina Sandström both reflect vividly upon their experiences of engaging in Nanabuatzin).

The mythic imagery embodied in a given dynamic is also a prompt to the imagination; and in some dynamics, the imagination plays a central role. In Nabual, for example, the participant makes a long, disorientating imaginary journey, with eyes closed, until the appearance - in imagination - of an animal guide. In Tonatiub (described on pp. 164 - 169 above), the participant imaginatively identifies with various elemental aspects of their being. It is also not uncommon for participants to describe the appearance of spontaneous images as they are working, and this perhaps explains the poetic nature of so many of the responses and snapshots contained in this book.

\section{Energy}

Structurally, the dynamics present in microcosm an invitation to participate in the Taller's overarching trajectory, as described by Eilon Morris,

Within these processes the performer/participant often seeks to raise their energy from that of everyday 'life' to a 'heroic' or 'epic' level of being. Núñez located these qualities along a vertical spectrum, the pinnacle of which is 'pure undifferentiated energy' (Morris, 2017: 173). ${ }^{41}$

If this schema, and the notion of verticality, suggests a linear direction, in fact the movement of energy within the dynamics is much more organic. Each dynamic is structured in such a way as to create an overall arc of energetic engagement through waves of alternating pace, intensity, expansion and contraction.

Brazilian scholar, Cassiano Sydow Quilici, noted, in his snapshot above, the experience of moving from a 'dense sensation' to a 'more subtle experience' during a workshop with Núñez in 2016. Similarly, Morris notes that the 'transformation of energy can be understood as a qualitative transformation,

41 For the schema to which Morris refers see Figure 11 on p.318. 
in the sense of moving from "coarse to subtle", and identifies that it is this qualitative transformation that is described through the notion of 'verticality' (Morris, 2017: 173). As Quilici pointed out, there are traditional practices which operate within the concept of the 'human body as a complex structure that connects dense and subtle energies' (pp. 187 - 188 above). One such tradition is Vajrayana Buddhism, from which Núñez derived the Black Hat Dance which forms one half of Citlalmina. He tells us that,

As the performer flows with [the dance], he is charged with energy. Certain subtle fluids are activated in our bodies through movement, and these fluids, together with consciously generated endorphine, produce in us a sensation of glowing brightness which purifies and invigorates the organism. These are the benefits of meditation in motion (p. 136 above).

Arguably, the other dynamics also function as meditation-in-movement forms with the capacity to activate effects on the level of the subtle or energy body which is seen to underlie the gross physical body. ${ }^{42}$ Thus, the 'raising of energy' does not refer merely to a process of becoming more physically energized, but rather to the refinement and cultivation of the subtle dimensions of the bodymind.

The dynamic Olmeca 1 embodies an image of raising the quality of energy - from a dense, earth-bound, horizontal plane to an uplifted, vertical 'flight'. The dynamic begins with participants in a supine, resting position, then moves to an exploration of the spine against the floor. From here, the central section of Olmeca 1 consists of a series of asana-like positions, all of which have been derived from pre-Hispanic statuary, and through which the participant moves incrementally from being horizontal on the ground to the final Eagle position, in which is the spine is fully vertical.

42 For a discussion of Citlalmina as an adaptation from Vajrayana Buddhism, see Middleton, D. and Plá, D. (2018) 'Adapting the Dharma: Buddhism and Contemporary Theatre Training' in Journal of Global Buddhism Vol. 19 (2018): 113-125 


\section{Olmeca 1}

Supine, resting position. Arms by the sides, palms down. Raising arms and legs, the spine is snaked and rubbed against the floor.

Chac Mool - reclining on the forearms, with feet on the floor and knees raised, head turned to the left. The body creates a ' $u$ ' shape.

Xochi Pilli - Sitting with legs crossed and feet raised off the floor, balancing on the sitting bones. The arms are held in front with the hands in a position that suggests the holding of invisible sticks or poles. The chin is lifted and the head dropped slightly back.

Squatting - with feet flat on the floor, elbows are against the inside of the knees with hands in prayer position, spine elongated.

El Acechador [the hunter/stalker] - Standing, angled forward from the hips, knees slightly bent. The arms reach slightly back, palms facing backwards. The chin is slightly tucked but the gaze is lifted.

La Aguila [the Eagle] - Standing on tip toes, knees bent, arms raised overhead.

Contemplative Running.

In this way, the dynamic is designed to allow the participant to explore the evolution from a horizontal orientation to the ground to a vertical orientation. This is an embodiment of the mythic image of Quetzalcoatl - the feathered serpent - an image which encapsulates the notion of the transformation of earth-bound, dense energy into the subtle dimensions of spiritual flight. The 'flight' that is embodied in the raised wing position of the Eagle is released into full expression in a closing cycle of contemplative running.

Each of the positions in Olmeca 1 is challenging to sustain, but, mindfully inhabited, they also hold the potential to act as psychophysical catalysts, releasing areas of tension and blockage and intensifying the participant's 
energetic presence. The 'asanas' do not follow immediately one upon the next, but are alternated with short periods of relaxation and release (and repeated in cycles of three). This alternation of contraction and release, intensification and relaxation, is a key principle of the dynamics (p. 158 above), and contributes to their energy-generating effect.

Rhythm plays an important role in conducting the energetic flow of the dynamics. Often, the rhythmic temperature is established and modulated through drumming, with Núñez - or, on occasion, an assistant - using a hand-held frame drum. At other times, the rhythm is created by the sound of the group's running or dancing feet.

In his discussion of two of the Taller's key tools, slow walking and contemplative running, Eilon Morris writes,

rhythm can be seen as both emerging from and acting upon the performer and the group. As they move through the space (sometimes slowly, sometimes fast) each participant generates their own rhythms and begins to tune into the rhythms of the others. This attunement (an entrainment of sorts) is one of the tools by which the performers become 'present', existing in the flow of the moment - what Núñez refers to as the 'actualized instant' (Morris, 2017: p.168).

The interplay of intra- and inter-personal rhythms that Morris describes is indeed both a focus for attention and a support to the stabilising and intensifying of that intention. The group's rhythmic attunement is, however, not solely the result of the group's interaction. Guiding the dynamics from within, Núñez drives the rhythm of the group, side-coaches to encourage continuous focus, and models, through his own participation, the process of raising, sustaining and modulating energetic output. Each individual, and the group as a whole, should be carried through waves of increasing and decreasing intensity and repeated cycles of action, until the dynamic culminates in a final release of energy. This involves a skillful conducting of the process by Núñez, and a conscious balancing of surrender and persistence 
by each participant; to lose control in the sense of giving way to a mindless and exhausting frenzy of movement or 'trancing out' is not desirable. Rather, heightened awareness is to be continually maintained: 'You have to watch your mind, it's like a meditation in movement, you have to be alert' (Núñez in Middleton \& Núñez, 2018: 223).

All of the dynamics end with the same closing process: from a final phase of contemplative running (in an anti-clockwise direction), and without stopping, the group come together, stepping clockwise, in a close circle. The step is derived from the Mexican conchero tradition and involves alternately crossing the right foot in front of, and then behind the left. This creates a centripetal-centrifugal pulse, at the same time as the rotation of the circle. With arms crossed in front of their moving bodies, the participants link hands and the circle turns with increasing speed until a final cry of Awa! (Now!) halts the movement, and the raised energy is released in a loud cry.

\section{Defining the Dynamics}

In closing, I would like to try to draw together these comments with the analytical summary of the dynamics with which I began, and to offer a definition of the dynamics that contains all of the characteristics that have been variously described as essential:

$A$ dynamic is a meditation-in-movement form comprised of energetic, attitudinal and imaginative gestures performed through a structured sequence of psychophysical actions. The sequencing entails continuous movement, changing rhythms, and alternation between processes of tension and relaxation, or contraction and expansion. The essential attitudinal foundation is one of continuous mindful focus upon the cultivation of inner qualities, as experienced through the lens of an embodied mythological image.

The dynamics represent more than forty years of assiduous practical research at the intersection between theatre, ritual, and meditational traditions. As such, they function equally as devices for actor-training and as devices for personal development. In Part One, Núñez wrote that with his understanding 
of 'here and now' and 'as if,' Stanislavski had 'left implanted in contemporary theatre a path which will lead us to the heart of the human being' (p. 54 above). The work of the Taller has also been to rigorously and tirelessly explore the creation of a path for the actor which leads to the heart - to the inner dimensions of our being. The dynamics are the central devices on that path, opening into the depths of experience and insight more usually associated with the world's meditational and ritual traditions.

\section{REFERENCES}

Middleton, Deborah (2016) Personal Notes from Swimming in the Inner Source: A workshop with Nicolás Núnez. University of Huddersfield, England, 31 May - 1 June 2016.

Middleton, Deborah (2018) Unpublished interview with Nicolás Núñez and Helena Guardia. Mexico City, 10/04/2018.

Middleton, Deborah \& Núñez, N. (2018) 'Immersive Awareness' in Theatre, Dance and Performance Training, 9:2, 217-233.

Morris, Eilon (2017) Rhythm in Acting and Performance. London: Bloomsbury Methuen. 